\title{
Dynamic SQL Knowledge As A Mechanism For Increasing Individual Absorptive Capacity
}

Tanya Beaulieu, Utah State University, USA

Pam Dupin-Bryant, Utah State University, USA

David Olsen, Utah State University, USA

\begin{abstract}
Technology continues to evolve rapidly, and organizations need to constantly evolve to keep up with the latest innovations in hardware, software, and processes to strategically select and manage technology. Underlying these firm capabilities are the employees that monitor, plan, and implement technology improvements, thereby it is critical that organizations have employees that can contribute to firm absorptive capacity and who can strategically take advantage of technology innovations. In this theoretical paper, we examine what type of curriculum MIS undergraduate programs might implement to prepare students for careers in the dynamically evolving realm of technology-infused organizations. We posit that students need to go beyond the adage of "learning how to learn", but instead need to have the skills and the mindset to compete in a technology-enabled environment. Specifically, we examine a learning module on Dynamic SQL delivered in an advanced database course, and analyze why introducing a rigorous and complex learning module can develop and expand students' absorptive capacity resulting in a competitive advantage when entering the workforce.
\end{abstract}

Keywords: Dynamic SQL, Absorptive Capacity, Competitive Advantage, Database, Pedagogy, Curriculum

\section{INTRODUCTION}

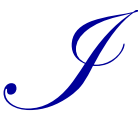

nnovation is a driving force for an organization's survival and growth (Audretsch, Keilbach, \& Lehmann, 2006; Cohen \& Levinthal, 1990) and can lead to disruptive environments which fundamentally change how value is generated and competitive advantage is maintained (Christensen, 2013). Nowhere is this more relevant than with technology. In less than 25 years, we have seen software development approaches migrate from a low level of maturity (Paulk, Curtis, Chrissis, \& Weber, 1993), to the advent of the waterfall method, only to be replaced by agile methodologies which is now being driven by the DevOps movement. Infrastructure is not immune to this dynamic environment where in-house data centers are rapidly migrating to cloud computing made possible by virtualization of servers, applications, and networks. Big data and analytics are becoming increasingly important, but force a different way of thinking about data as structured data and relational databases give way to NoSQL and Hadoop supported data lakes.

Fueled by innovations such as virtualization, Information Technology (IT) services are becoming increasingly distributed and the very nature of the IT workforce must adapt. IT workers will be moving out of core business organizations and instead work for IT service providers. Employees left in non-IT businesses will need to network with an ever increasing array of providers to pick and choose how technology is formulated to work for their needs. Similarly, IT service firms will be working with an increasing number of heterogeneous clients, with varying needs. Employees for IT Service firms and Non-IT firms alike will need to respond to this dynamic hypercompetitive pace of technology-induced change (Antero, 2012). Therefore, technology workers face unique challenges to keep informed and remain relevant.

In this paper, we are inspired by the question: How can we develop in our students the technology capabilities needed for an innovative technology infused workplace? Through the lens of capabilities and absorptive capacity 
(Cohen \& Levinthal, 1990; Zahra \& George, 2002) we analyze why exposing students to complexity increases their personal absorptive capacity and, as a result, prepares students not only with useful skills, but also an appreciation of the challenges faced in a dynamic workplace. Inspired by the themes and ideas of John Dewey and other proponents of pragmatic, progressive education, we maintain that education should focus less on facts and immutable laws, but instead on practical uses, successful rules for action, and the cultivation of dynamic, adaptable minds. To this end, we illustrate how curriculum in the Management Information Systems (MIS) discipline can engage, support, and develop individual absorptive capacities thereby producing students ready to take on roles in technology-oriented organizations.

\section{LITERATURE}

Absorptive capacity (ACAP) addresses how knowledge is gained and utilized for a competitive advantage. Cohen and Levinthal (1990) define ACAP as "the capacity to recognize the value of new external information, assimilate it and apply it to commercial ends" (p. 128). ACAP is driven by the idea that prior related knowledge is needed in order to identify, assimilate and use new knowledge. Prior knowledge facilitates searching and the recognition of new information that is valuable and relevant. Once identified, knowledge must be assimilated and added to the current knowledge base. Once new knowledge becomes a part of the knowledge base, it must be exploited toward strategic goals. This process occurs iteratively and is cumulative; as a result, over time, ACAP increases. The intensity of effort required in this process is an important component with higher levels of intensity resulting in higher ACAP.

Zahra and George (2002) extended Cohen and Levinthal's (1990) conception by proposing an expanded model of ACAP. In the Zahra and George model, the antecedent condition of external knowledge and prior experience remains. However, the concept of ACAP is said to be comprised of both potential ACAP and realized ACAP. Potential ACAP captures the degree to which a firm is alert and able to acquire and assimilate external knowledge. Realized ACAP involves the transformation of newly acquired information into a firm's knowledge base, and then exploiting the knowledge in useful ways. Also added to the Zahra and George (2002) model are moderators between these direct relationships. Activation triggers which may be external or internal act as a stimulus to activate the acquisition of knowledge. For example, Kim (1998) showed how an internal crisis at Hyundai incited the acquisition of new knowledge and turned the company from an imitator to an innovator. Zahra and George (2002) also note a moderating social integration mechanism which relies on communication patterns and structures that allow the newly acquired knowledge to become available to other organizational members for transformation and exploitation. See Figure 1.

Figure 1. A Model of Absorptive Capacity (Zahra \& George, 2002)

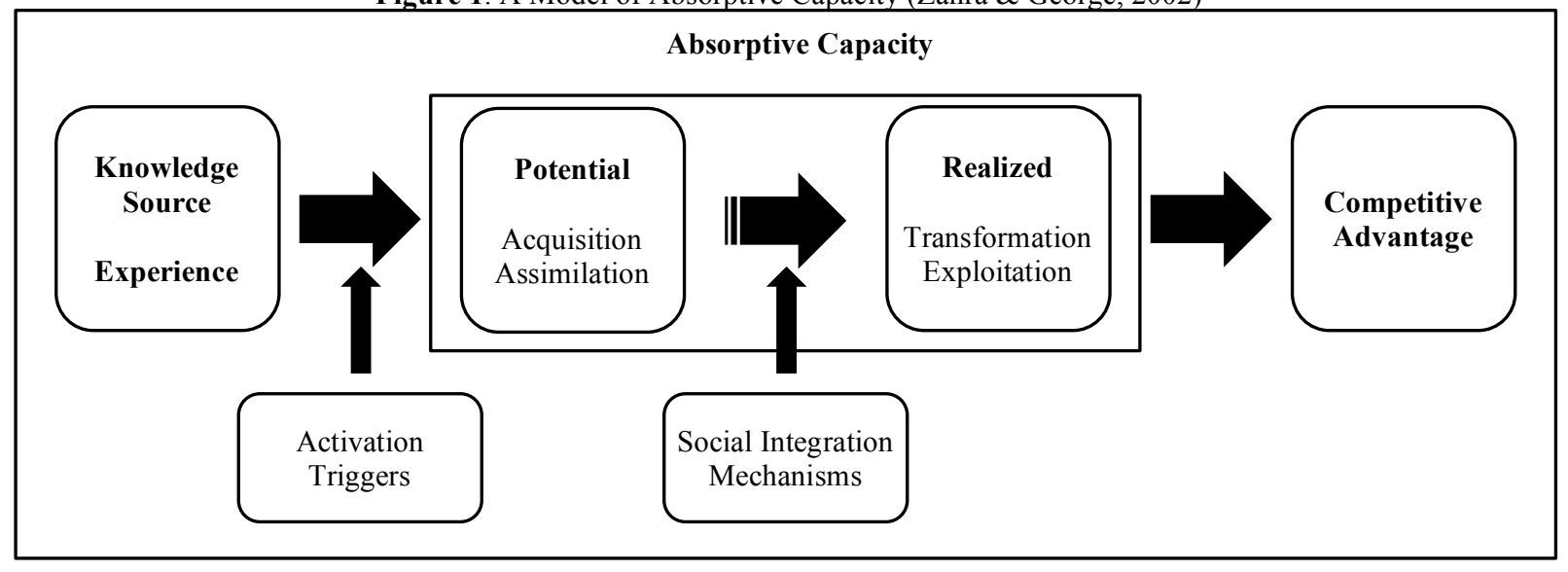

ACAP is a multidimensional construct, and while generally studied at a firm level or even macro-economic level (e.g., Criscuolo \& Narula, 2008), there can be significant benefits to understanding ACAP at an individual level. 
Given that Cohen and Levinthal's (1990) research has its root in the cognitive levels of learning and problem solving, the concepts of ACAP may also be conceptualized at the individual level (Da Silva \& Davis, 2011). Any conception of organizational strategy should start with people, as "people are the only true agents in business" (Sveiby, 2001, p. 345). Ignoring the individual in ACAP ignores the fundamental assumption that knowledge processing occurs through personal knowledge and mental maps which integrates knowledge in unique and valuable ways (Lane, Koka, \& Pathak, 2006). Thus, human IT resources with the knowledge and skills to assess and exploit new technology are able to bring value to the firm (Chengalur-Smith, Nevo, \& Demertzoglou, 2010). We define an individual's absorptive capacity as a measure of how well an individual can use their skills and knowledge to realize a benefit. Considering it is individuals' that are responsible for searching, seeking, making decisions, and exploiting knowledge in order to make strategic decisions which will lead to firm value, analyzing ACAP from an individual human resource standpoint is important.

Absorptive capacity corresponds with many of the core themes and ideas of John Dewey and other advocates of pragmatic, progressive education. These themes emphasize the importance of human development, problem solving, critical thinking, practicality, experience, and the cultivation of learners who are open and willing to the challenge of change (Gutek, 2000; Murphy, 2006). Dewey (1897), a prolific pragmatist philosopher and progressive educator suggested:

it is impossible to prepare the child for any precise set of conditions. To prepare him for the future life means to give him command of himself; it means so to train him that he will have the full and ready use of all his capacities; that his eye and ear and hand may be tools ready to command, that his judgment may be capable of grasping the conditions under which it has to work, and the executive forces be trained to act economically and efficiently ( $\mathbf{9} 6$ ).

As with ACAP, progressive education focuses on utilizing prior experience and knowledge sources. Activities and methods are focused on helping individuals learn to succeed in varied situations and environments, by learning to apply and adapt their skills and knowledge. Educators seek to cultivate in learners "a dynamic, adaptable mind which will be resourceful and enterprising in all situations, the mind which will have powers to create values in an unknown future." (Shawal, n.d., I 24). The point behind pragmatic education is to prepare students for the actual problems that might be faced in an actual work environment.

Preparing students for technology careers goes beyond teaching those skills and technologies which are currently in fashion. Instead, employers are looking to hire students with a variety of skills and capabilities (Bailey \& Stefaniak, 1999; Gallagher, Kaiser, Simon, Beath, \& Goles, 2010). This variety may broadly be thought of as technical skills and non-technical skills, where technical skills may be specific to a type of hardware, or software, and non-technical skills focus on business, management, and communication skills (Hawk et al., 2012). To accommodate this variety, educators, need to go beyond the teaching of specific technical tools. We believe while the adage of learning how to learn (Ellis, 1965) still holds, also critical in today's workforce is the ability to be adaptable in a rapidly changing and unpredictable environment. We interpret this as encouraging dynamic capabilities in students (Teece, Pisano, \& Shuen, 1997). Student learning involves both learning capabilities, which involves the assimilation of new knowledge, as well as problem solving capabilities, which results in the creation of new knowledge (Cohen \& Levinthal, 1990). These two capabilities are interconnected and involve making associations that might not otherwise be made (Da Silva \& Davis, 2011). Learning theory suggests that higher intensity of instruction leads to more in-depth learning, which consequently allows for better assimilation of and forming linkages between prior and new knowledge in an effort to solve complex problems. Drawing on concepts from dynamic capabilities, and using an absorptive capacity lens, the goal of this paper is to present a framework for understanding how introducing complex and rigorous topics can increase students' absorptive capacity, and in turn, better prepare students for technology careers.

\section{ILLUSTRATION OF MIS CURRICULUM TO DEVELOP INDIVIDUAL ABSORPTIVE CAPABILITY}

The following Dynamic SQL Module was designed to expose students to an innovative and provocative concept utilized in the field of database management. The module was designed to help students increase their capacity to recognize variable and external information they may encounter when designing queries, assimilate the information, 
and apply it to their query designs in an educational setting and consequentially their future workplace. This module is part of a series presented throughout the semester designed to evoke an intensity of learning. The module's rigor and complexity facilitate the transformation of students' potential ACAP to realized ACAP, thereby building a foundation for increased absorptive capacity and competitive advantage in the workforce.

We highlight the topic of Dynamic SQL in this paper as an example, recognizing there are other rigorous database topics which would also benefit students. Undoubtedly, other advanced database topics could similarly increase students' ACAP. In fact, we recommend building a solid foundation of core database skills and knowledge in an introductory database course, and then within an advanced database course, exposing students to several advanced topics beyond dynamic SQL. However, we highlight Dynamic SQL in this article as it is particularly apt for several reasons. First, Dynamic SQL is a marker of advanced understanding because one must have a basic understanding of databases before starting Dynamic SQL and one must master advanced concepts to be proficient at Dynamic SQL. Second, one must have an understanding of the local database, servers and data communication systems to effectively make use of Dynamic SQL. Third, Dynamic SQL is frequently a productivity enhancement tool because it is used to automate repetitive tasks, it will work in any database or server, and it is used to generate code that adjusts itself to changing conditions. Indeed, anything that helps students and novice database workers to be more productive is important because productivity is often used to judge performance.

This module was designed as a stand-alone activity and has been successfully applied in various upper division university database courses. The module can be easily adapted to any advanced university database course as long as students who participate have extensive prior knowledge of conventional database principles and a strong SQL background. While the subsequent outline provides a strategy for integrating Dynamic SQL principles into the curriculum, it is by all means not exhaustive. Instructors are encouraged to therefore adapt, assimilate, and apply this Dynamic SQL Module as they deem appropriate. The underlying principle is to encourage database educators to explore methods in the IS classroom that expose students to innovative concepts that will help them increase their absorptive capacity and meet marketplace expectations.

This module assumes students have access to Microsoft SQL Server (2005 or newer) Management Studio and access to a database. This module has been tested using a standard stock market trading database (DDL used to build the tables is included in the Appendix). The specific stock market data set used in this module may not be readily available; however, any comparable data may be substituted into the educational framework provided to ensure students are exposed to the concepts of Dynamic SQL.

The Dynamic SQL module was designed to be completed over a two-week period. First, two 75-minute in class sessions serve as the basis for leveraging previous database knowledge in introducing the concept of Dynamic SQL. The synchronous, face to face sessions with the instructor allow students time to experiment with diverse queries, acquire new skills, and assimilate new knowledge. Second, students are assigned an out of class activity which helps them exploit their new knowledge and apply Dynamic SQL for realized gains. This ambitious time frame provides the intensity of learning environment which mimics the stringent time constraints often thrust upon database programmers. However, the module could easily be adapted to longer time periods.

The content of the Dynamic SQL module corresponds with Zahra and George's Model of Absorptive Capacity (2002) and served as inspiration for the Dynamic SQL module's development and design. Figure 2 (A Simplified Model of Absorptive Capacity) will be used as an overlay to introduce and expound on the Dynamic SQL module development. Through this module students learn not only a technical skill, but also the business benefits and challenges involved in using the technology. As the following section demonstrates, the Dynamic SQL module develops a student's dynamic capability and leads to increased absorptive capacity. In other words, since Dynamic SQL is unlike any other 'basic' database curriculum, it enables students to gain the ability to change, alter, and transform their current database capabilities.

\section{Knowledge Source and Experience}

The theory of absorptive capacity suggests that prior knowledge and experience is needed to search for and understand the relevance of new information (Cohen \& Levinthal, 1990). Prior knowledge may be from an external 
source such as an instructor or a textbook. External sources are judged for their trustworthiness and importance, with higher weight placed on external sources that are found knowledgeable and applicable. Internal knowledge sources, such as a student's prior knowledge or experiences also provides an important component in the absorptive capacity framework. Prior knowledge is based in recollections, and studies have found that storing and recalling information is easier when prior knowledge about the topic is present (Barfield, 1986). This idea is related to associative learning which conceives of knowledge as a network structure. The more connections that are made, the easier it is to integrate new knowledge (Wickens, Gordon, Liu, \& Lee, 1998). Concepts, in isolation are difficult to make sense of, but when placed within a body of knowledge and within a familiar context, the concept is then readily learned (Lindsay \& Norman, 1972). Existing prior knowledge explains several phenomena such as students with strong algebra skills tend to learn calculus more easily (Ellis, 1965) and why students who know one programming language find it easier to learn a second programming language (Anderson, Farrell, \& Sauers, 1984).

Figure 2. A Simplified Model of Absorptive Capacity

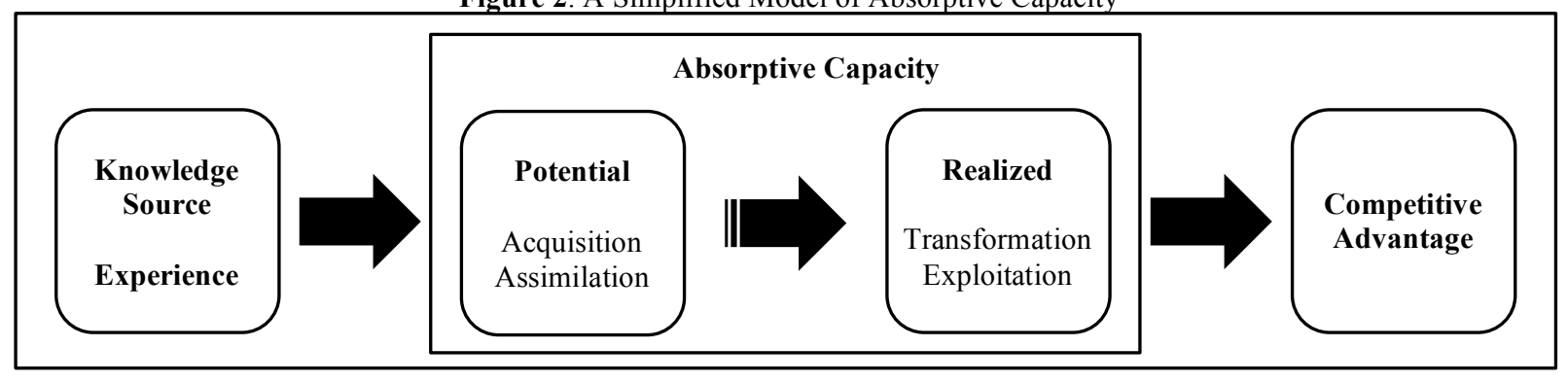

\section{Background Material}

Since this module is suggested for advanced database courses, the instructor should have already assessed student knowledge and skills related to the relational database model, basic queries, etc. However, background/additional resources should be provided to students on the course learning management system (LMS) in case students need to refresh their knowledge/skills. At the beginning of the Dynamic SQL module, the instructor presents standard queries. The instructor gives examples of the most pertinent prerequisite competencies in order to help activate student's prior knowledge. A list of required competencies is listed in Table 1.

\section{Introduce Dynamic SQL}

The instructor would then conduct a discussion about Dynamic SQL and how learning this skill may help students achieve a competitive advantage. Students have a competitive advantage knowing Dynamic SQL because it is thought to be a harder and more valuable database technique. The instructor may describe the ongoing debate over the validity of Dynamic SQL and why it is an important part of each data professional's arsenal. Sharing stories of how an understanding of this powerful concept can help convert boundless data into meaningful information used for business decision-making. Content for this introduction can be found online, in course textbooks, or from a variety of references identified in this manuscript. One example is http://stackoverflow.com/ and another is http://www.sqlservercentral.com/.

Table 1. List of Prerequisite Competencies Prerequisite Database Competencies

Understand the Relational Database Model

Understand the concept of object types in a database and be familiar with common objects

Identify the component parts of the database, including: tables, attributes, tuples, relationship, primary key, foreign key

Write basic query statements, including: SELECT, FROM, WHERE, DELETE, UPDATE

Use common operators, such as: BETWEEN, LIKE, IN, NOT, AND, OR, UNION, INTERSECT

Use common clauses, including: ORDER BY, JOIN, HAVING

Use SQL Functions, such as: AVG( ), COUNT( ), MIN( ), MAX( ), SUM( ), UPPER( ) 
During this introduction the instructor also introduces the learning objectives. The learning objectives should be highlighted in an easy to read format and posted on the course Learning Management System (LMS) for easy recovery and student access. For the module, suggested learning outcomes include: a) the ability to write Dynamic SQL statements, b) an understanding of the strategic use of Dynamic SQL, and c) the ability to converse with others about the pros and cons of Dynamic SQL.

The introduction of the module provides the student both a reminder of their personal internal knowledge and experiences such as the concepts illustrated in Table 1. Students recalling their prior knowledge provides a bridge to linking the newly introduced information to their prior knowledge and helping to assimilate the new knowledge. Bringing in a discussion of business implications - both benefits and challenges confirms the validity and relevant nature of the lesson, and establishes the trustworthiness of this external source of knowledge.

\section{Potential}

Potential absorptive capacity is the ability to acquire, and assimilate prior knowledge and experiences. Acquiring information is the process of finding and identifying relevant information. For a student, this would entail remembering pertinent information from prior lessons, and having confidence that the information presented by the instructor is relevant and accurate. At the firm level, assimilating knowledge is how a firm uses its routines and processes which "allow it to analyze, process, interpret, and understand the information obtained from external sources" (Zahra \& George, 2002, p. 18). Instructors within a classroom can facilitate the assimilation of knowledge by developing their own classroom routines and processes for presenting new information. The distinction between potential and realized ACAP has been illustrated at the firm level as the difference between a firm having a patent (potential ACAP), and commercializing the patent (realized ACAP) (Joshi, Lei, Datta, \& Shu, 2010). At an individual level, the difference has been demonstrated in an academic research setting as the difference between creativity and the ability to generate research ideas (potential ACAP), and the writing and publication of these ideas (realized ACAP) (Da Silva \& Davis, 2011). Similarly, in an educational setting, we conceive potential ACAP as the ability of a student to engage in the lesson and understand the lesson presented. These abilities may lie in individual differences such as self-efficacy (Axtell et al., 2000), persistence (Taggar, 2002), and individual motivation (Minbaeva, Makela, \& Rabbiosi, 2007). Despite individual differences, we contend that the activities presented have the potential to increase all students' ACAP, although we realize the foundational level of ACAP and the amount of increase may vary by a student's individual differences.

\section{Dynamic SQL Examples}

After introducing the topic, the instructor begins to grind through examples. The instructor proceeds to walk the students through several examples that increase in complexity. At which time, students are then asked to complete the In-Class Activity listed in Table 2. The instructor models the behavior and the student then tries to reproduce the behavior. During this example phase students are acquiring the requisite skills, they are getting their feet wet, where the resulting queries are not as important as the attempt. Students may simply replicate the instructor's statements in order to achieve success.

Students are asked to create two stored procedures similar to each of the 4 examples provided. They will acquire the new knowledge by writing a total of 8 stored procedures. Students are asked to show each stored procedure, the output, and then they are asked to provide a short explanation as to what they were trying to do with the stored procedure. They are encouraged to justify the usefulness of each stored procedure. After the stored procedures are executed, a class discussion is held where students can reflect on the strategic use of Dynamic SQL. Adding these reflective steps to the process facilities the assimilation process, and helps meet the learning objectives of understanding and being able to apply Dynamic SQL strategically. 
Table 2. Dynamic SQL - In-Class Activity

\section{Dynamic SQL - In Class Activity}

- Create two stored procedures similar to each example (items $1-4)$ provided below.

This means you will write eight stored procedures.

- For each stored procedure, show the following:

○ the stored procedure syntax,

the output,

a short explanation as to what you were trying to do with the stored procedure, and

justify the usefulness of the stored procedure.

- Think about the pros and cons of Dynamic SQL and be prepared to discuss in class.

1. Create a stored procedure that returns the company name and city given that the TickerSymbol is passed as an input parameter. Execute the procedure for the Apple stock.

CREATE PROCEDURE StockName @TickerSymbol CHAR(10)

AS

SELECT CompanyName, City

FROM CompanyInformation

GO

WHERE TickerSymbol = eTickerSymbol

EXEC StockName AAPL

2. Create a stored procedure that will list all the tuples and all the attributes for a given table. The table name must be passed as a parameter to the stored procedure.

CREATE PROCEDURE AnYTableSelect @TableName VarChar(100)

AS

SELECT * FROM @TableName

-- Server: Msg 137, Level 15, State 2, Procedure AnyTableSelect, Line 3

-- Must declare the table variable "@TableName".

This approach doesn't work because SQL Server will not pass object names as parameters.

However, another approach will work which is called 'Dynamic SQL.'

DROP PROCEDURE AnYTableselect -- EXECUTE DROP STATEMENT FIRST AND THEN THE STATEMENT BELOW

Create Procedure AnyTableselect @TableName VarChar(100)

AS

Declare @SQL VarChar(1000)

SELECT QSQL $=$ 'SELECT * FROM '

SELECT @SQL = @SQL + @TableName

EXEC (@SQL)

$\mathrm{GO}$

EXEC AnyTableselect StockData

3. Create a stored procedure that lists all the tuples and all attributes of the StockData table for a given list of TickerSymbols. The list of Tickersymbols must be passed as a parameter to the stored procedure.

CREATE PROCEDURE FindStocks @TickerSymbol VarChar(100)

AS

SELECT *

FROM StockData

GO

WHERE TickerSymbol IN (@TickerSymbol)

EXEC FindStocks "AAPL, F"

-- THE STATEMENT RESULTS IN ZERO RECORDS.

This approach doesn't work because a variable cannot be passed to the IN clause.

The following works because we build a string of SQL commands that are executed

dynamically.

DROP PROCEDURE FindStocks -- EXECUTE DROP STATEMENT FIRST AND THEN THE STATEMENT BELOW

CREATE PROCEDURE FindStocks ATickerSymbol VarChar(100)

AS

DECLARE @SQL VARCHAR (1000)

SELECT @SQL = 'SELECT * FROM StockData '

SELECT @SQL = @SQL + ' WHERE TickerSymbol IN (' + eTickerSymbol +')'

EXEC (QSQL)

GO

EXEC FindStocks "'AAPL', ' F'"

(Table 2 continued on next page) 
(Table 2 continued)

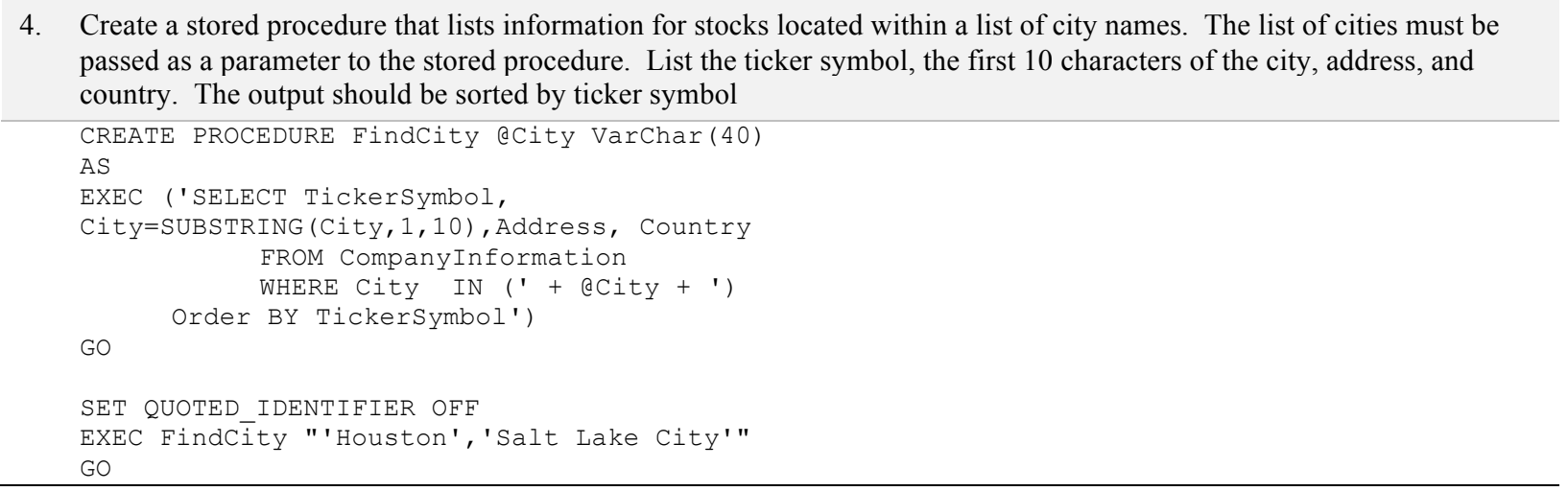

This process involves the student using prior knowledge and experiences in order to identify, acquire, and assimilate the new knowledge. Students first watch the instructor demonstrate Dynamic SQL. During the demonstration, the student is able to compare Dynamic DQL with Static SQL, and note the similarities and differences. The concept of a database object, which might be a bit nebulous in a student's mind at the beginning of the lesson is more clearly defined by the end of the lesson. The student has had the opportunity to watch examples, and then repeat examples with increasing complexities within class. This process of assimilation is more effective when modules are structured in a similar way throughout the class. For example, an effective instructional strategy might be that all new modules begin with an introduction to the topic, a reminder of previous pertinent concepts, a discussion of the business implications of using the specific technique, the instructor demonstrates the technique, and then students are given an opportunity within class to practice what was demonstrated through increasingly complex prompts. Creating a classroom learning routine provides a consistent structure that supports the knowledge assimilation process.

\section{Realized}

Realized absorptive capacity is the ability to transform and exploit the new knowledge. The transformation process is the transformation of new and prior knowledge into a transformed knowledge base. The transformation process may refine or even delete prior knowledge. The consequence is that the resulting knowledge resides at a deeper and more robust level of understanding. The transformation process is subject to the bisociation process (Koestler, 1964) whereby two "apparently incongruous sets of information are combined to arrive at a new schema" (Zahra \& George, 2002, p. 190). Exploitation is the ability to use the newly transformed knowledge to a benefit. In a student setting, exploitation might be the process whereby a student is able to use Dynamic SQL outside the classroom in a take home assignment, or perhaps to discuss its use and even demonstrate Dynamic SQL during a job interview. 
Table 3. Dynamic SQL - Take Home Activity

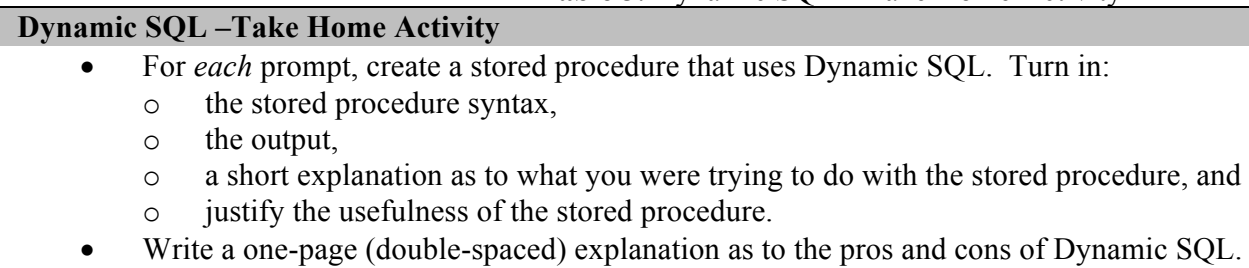

1. Create a stored procedure that allows for dynamic inputs for an industry. Put the SQL statement into a variable called (a)sql and give it the datatype VARCHAR(1000).

Note: A user does not know the industry needed for a query until runtime.

Possible Answer:

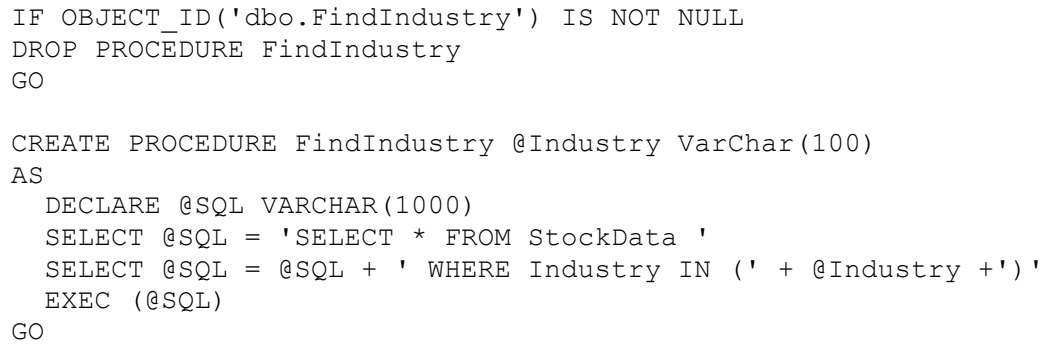

2. You are suspicious that stocks close on average higher during certain groups of days of the week than other days of the week. Create a stored procedure that allows for dynamic inputs of days of the week. The stored procedure should return the average closing price for those groups of days. Put the SQL statement into a variable called @sql and give it the datatype VARCHAR(1000).

Possible Answer:

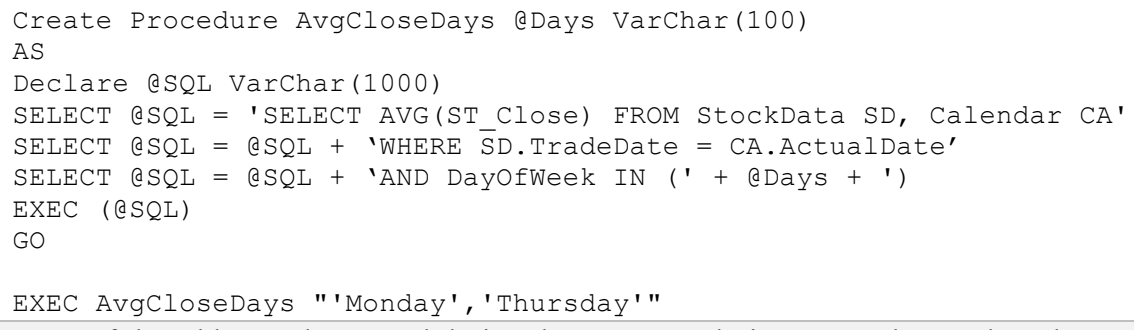

3. Using any of the tables we have used during the semester, design a stored procedure that uses Dynamic SQL. For full credit, the SQL statement must require Dynamic SQL, that is, it could not be executed using static SQL.

The transformation process begins with the in-class discussion which compares and contrasts Static SQL with Dynamic SQL. Bisociation occurs with the in-class activity, especially in prompts 2 and 3 where the student is encouraged to try to solve the prompt using what logically might seem appropriate, only to be presented with an error message. The dichotomy between what seems logical, and what is allowed syntactically must be resolved, and as a result, the knowledge of the student is transformed with a much deeper understanding toward how SQL functions. The exploitation process is the end result, and the proof that the new knowledge has been transformed and that the student is able to demonstrate the ability to solve complex problems independently. The last prompt of the take-home assignment provides ample opportunity to demonstrate the exploitation of knowledge because the student must conceive of an appropriate use of Dynamic SQL, and then create a solution.

\section{Competitive Advantage}

As a result of the Dynamic SQL module, the student's absorptive capacity has increased by both breadth and depth. In addition to acquiring a new skill, both in-class discussion and written input from the student on the strategic 
implications of Dynamic SQL provides a holistic approach that enables the transformation of knowledge and an increased absorptive capacity. When students enter the job market, and the workforce, this experience provides for a competitive advantage for several reasons. First, recruiters are increasingly turning to automated technologies including data mining and semantic analysis to provide a first cut of prospective new hires (Bizer et al., 2005), therefore including the terms "Dynamic SQL" or "Advanced SQL" on a resume is advantageous as the words alone may help differentiate one candidate from another. Second, Dynamic SQL signals advanced SQL skills, which is highly sought after in the current data science hiring environment. Positive signals from a resume spill over into the job interviews in that pre-interview evaluations tend to have "self-fulfilling effects" during the interview (Dipboye, 1982), thus giving students familiar with Dynamic SQL an advantage in the job interview. Third, because the Dynamic SQL module goes beyond just teaching the skill, but also emphasizes strategy and business implications, students, as a result of the module, are able to intelligently discuss Dynamic SQL using discourse similar to those in the workforce. Studies have shown, potential employers are more positive toward prospective hires when their language (i.e., discourse) is similar to that of the organization (Bergström \& Knights, 2006). And finally, for technical positions, it is becoming increasingly popular during an interview, for interviewees to be asked to demonstrate claimed skills. Because of their strong absorptive capacities, it is not difficult to conceive that students will be aptly able to demonstrate these complex queries involving joins, and perhaps sub-query statements as these skills have been continually reinforced during the learning process of the advanced topics.

\section{CONCLUSION}

The objective of this paper was to theoretically examine why teaching difficult and rigorous material, such as the Dynamic SQL module, increases student's absorptive capacity giving them a competitive advantage in the job market. While many of the techniques noted above are common teaching practices, we provide in this paper, a deeper understanding by applying the theoretical lens of absorptive capacity in order to better understand why these techniques are successful. A summary of recommendations along with the corresponding ACAP principle is summarized in Table 4. Table 4 also provides explicit references into the Dynamic SQL Module used for illustration purposes.

We selected the Dynamic SQL module due to its complex and rigorous nature. We propose that courses which involve increasing complexity are good candidates for increasing absorptive capacity. Within the MIS curriculum this may involve skill-based courses such as database and coding, as well as upper division strategy and design courses. Course which focus on breadth, such as those set up as independent modules that do not build on each other, may not in and of themselves increase absorptive capacity. However, even breadth courses can provide a foundation of experience and recollections which might be called upon in building future absorptive capacity. 
Table 4. Summary of Recommendations

\begin{tabular}{l|l|l}
\hline \multicolumn{1}{|c|}{ Recommendation } & \multicolumn{1}{c}{$\begin{array}{c}\text { ACAP Principle } \\
\text { Knowledge Source }\end{array}$} & \multicolumn{1}{c}{ Example from Module } \\
\hline $\begin{array}{l}\text { Instructor should be knowledgeable and } \\
\text { experienced in teaching the module. } \\
\text { Textbooks, when used, need to instill } \\
\text { confidence in students. }\end{array}$ & $\begin{array}{l}\text { External sources are judged by their } \\
\text { trustworthiness and importance. }\end{array}$ & $\begin{array}{l}\text { Experienced professor teaches the model } \\
\text { using a textbook from a leading textbook } \\
\text { publisher. }\end{array}$ \\
\hline
\end{tabular}

in students.

\section{Experience}

Review and practice problems during inclass session to help recollect prior knowledge and form a bridge for new knowledge.
Prior knowledge is accessed via recollections from past lectures and past homework enabling students to understand the value and relevancy of new information being created

\section{Knowledge Source}

Discussion of the relevancy of the topic, sharing stories about its use in the workforce, and the challenges and benefits.

Demonstrate problems and ask students to solve problems of increasing complexity.

\section{Provides the relevant background to} prepare for acquiring new knowledge and establishes its relevancy.

\section{Potential ACAP - Acquisition}

Prior knowledge is used to understand its unique features

\section{Potential ACAP - Assimilation}

Incorporate an instructional routine such that each unit is taught using a consistent structure.
New information is easier to assimilate when it is presented in a familiar format and structure.
In class review of pertinent SQL with inclass examples and practice problems.
Placing the use of Dynamic SQL as a marketable skill ensures students understand the relevancy of the topic.

\section{Potential ACAP - Assimilation}

In class activity is followed by a discussion of strategic use.

Present problems that cannot be solved by current knowledge.
Being able to personally reflect on the topic provides a means of assimilation of new knowledge.

\section{Realized ACAP - Transformation}

The bisociation process allows incongruent sets of information to be combined therefore forming new knowledge.
Students are asked to solve problems in class to get their feet wet; to increase the complexity, students are asked to create their own queries and justify their use.

Throughout the semester, students first observe a demonstration, next students replicate what was demonstrated, third, students are asked to solve a new type of problem, followed by an in-class discussion and sharing of ideas.

Once students have experienced using dynamic SQL, they are more capable of discussing its strategic use.

Students are asked to write what seems like a standard query (See Table 2, Problems $2 \& 3$ ), but which cannot be handled using their current SQL knowledge. Dynamic SQL is the key to combining prior information into new knowledge.

\section{Realized ACAP - Transformation}

Ask students to solve problems that are rigorous and difficult.

Higher intensity of effort results in higher ACAP.

\section{Realized ACAP - Exploitation}

Out of class activity to solidify and demonstrate knowledge

In homework assigned, (See Table 3), Exploitation is successfully reached when students demonstrate a rich understanding of the topic through use of and communicating to others about the topic.
Out of class activity with ambitious timeframe creates higher intensity efforts and prepares students for the workforce. students begin with queries similar to those created in class thereby solidifying the transformation process. Exploitation of the knowledge is reached when students are able to propose a problem and a solution, and then discuss in written form the strategic use of dynamic SQL. 
While this paper is of a theoretical nature, future research could design a study to better analyze the strength and interactions among these principles and theorized outcomes. We can offer at this point some antidotal evidence and experience from teaching complex topics. First, students don't always love it. While some students embrace the rigor, and raise to the challenge, others can feel a bit overwhelmed. As educators, we find that when students struggle it is often because they are attempting to exploit knowledge that has not been properly acquired, assimilated, or transformed. For these students, it is helpful to go back to a base of knowledge where the student feels competent (i.e., they can successfully exploit the knowledge), and then move forward to ensure that each step along the ACAP path has been executed sufficiently. We find at the end of the course, or after students have received good job offers and are in the workforce, they look back and have a feeling of confidence and pride in what they accomplished during the course. It is not uncommon to hear a student express these sentiments in statements similar to: "Thank you for pushing us so hard in class, it has really paid off in my current job" or "Wow - I didn't think I could do it, but I kept trying, and I finally got it!" These are signs of absorptive capacity being expanded and successful outcomes.

Educating students that are productive employees is a laudable goal. This is a particularly difficult task in technology-intensive fields due to the hypercompetitive pace at which firms are adopting new technologies. Students must not only have the requisite skills, but the most sought after students will also have dynamic capabilities that can keep pace with technology changes. One result of the development of dynamic capabilities within students is an increase of their absorptive capacity. By providing rigorous and complex learning units, such as the Dynamic SQL module presented here, students, using their prior knowledge, and information from external sources such as instructors and textbooks, are able to identify and assimilate this new knowledge. This results in a transformation of the information which leads to the ability to exploit or use this knowledge independently. This realized absorptive capacity provides a foundation for further expansion of one's absorptive capacity, and leads to a competitive advantage when entering the workforce.

\section{AUTHOR BIOGRAPHIES}

Tanya Beaulieu is an assistant professor at Utah State University, Jon M. Huntsman School of Business, UT, USA. She received her $\mathrm{PhD}$ in management information systems from Washington State University. Her research interests include communication in online communities, crowdfunding, and entrepreneur's use of technology. She has published in outlets such as MIS Quarterly, Communications of the Association for Information Systems, and the Journal of Computer Information Systems, as well as proceedings such as the International Conference of Information Systems (ICIS). She previously served as the Managing Editor of the Journal of the Association for Information Systems (JAIS), and is currently serving as an Associate Editor for Communications of the Association for Information Systems. Prior to her PhD, Dr. Beaulieu owned a software development and consulting firm specializing in custom software development for large enterprise systems.

Pam Dupin-Bryant is a Professor of Management Information Systems in the Jon M. Huntsman School of Business at Utah State University. She earned her Ph.D. at the University of Wyoming and her master's and bachelor's degrees at USU. Throughout her career, Dr. Dupin-Bryant has employed a wide variety of delivery methods and educational strategies to facilitate learning for traditional and nontraditional students. Her research and scholarly writings have focused primarily on information systems pedagogy, e-learning/distance education, and business ethics. Her primary teaching activities include business applications programming, web design/development, and principles of MIS. Dr. Dupin-Bryant has received many awards for her teaching innovations, research, and service.

David Olsen received his Ph.D. in Management Information Systems from The University of Arizona in 1993 and taught at The University of Akron accounting department in accounting information systems for five years. Dr. Olsen joined the MIS department at Utah State University in 1998 and teaches primarily in the database area as well as the MBA strategy and management course. His research interests include database concurrency control, accounting information systems, the integration of SQL, XML and XBRL, and database modeling. His research has been published in journals such as Communications of the ACM, Issues in Accounting Education, and the Journal of Database Management and has published more than 70 articles in journals and conferences and is the MIS Department Head in the Jon. M. Huntsman School of Business at Utah State University. Dr. Olsen is happiest with the influence he has had on students, particularly influences related to students dominating in their careers. 


\section{REFERENCES}

Anderson, J. R., Farrell, R., \& Sauers, R. (1984). Learning to program in LISP. Cognitive Science, 8(2), 87-129.

Antero, M. (2012). Hypercompetition in the ERP industry. Americas Conference on Information Systems (AMCIS) 2012 Proceedings.

Audretsch, D. B., Keilbach, M. C., \& Lehmann, E. E. (2006). Entrepreneurship and economic growth: Oxford University Press.

Axtell, C. M., Holman, D. J., Unsworth, K. L., Wall, T. D., Waterson, P. E., \& Harrington, E. (2000). Shopfloor innovation: Facilitating the suggestion and implementation of ideas. Journal of Occupational and Organizational Psychology, 73(3), 265-285.

Bailey, J. L., \& Stefaniak, G. (1999). Preparing the information technology workforce for the new millennium. ACM SIGCPR Computer Personnel, 20(4), 4-15.

Barfield, W. (1986). Expert-novice differences for software: Implications for problem-solving and knowledge acquisition. Behaviour \& Information Technology, 5(1), 15-29.

Bergström, O., \& Knights, D. (2006). Organizational discourse and subjectivity Subjectification during processes of recruitment. Human Relations, 59(3), 351-377.

Bizer, C., Heese, R., Mochol, M., Oldakowski, R., Tolksdorf, R., \& Eckstein, R. (2005). The impact of semantic web technologies on job recruitment processes Wirtschaftsinformatik 2005 (pp. 1367-1381): Springer.

Chengalur-Smith, I., Nevo, S., \& Demertzoglou, P. (2010). An empirical analysis of the business value of open source infrastructure technologies. Journal of the Association for Information Systems, 11(11), 708-729.

Christensen, C. (2013). The innovator's dilemma: When new technologies cause great firms to fail. Harvard Business Review Press.

Cohen, W. M., \& Levinthal, D. A. (1990). Absorptive capacity: A new perspective on learning and innovation. Administrative Science Quarterly, 35(1), 128-152.

Criscuolo, P., \& Narula, R. (2008). A novel approach to national technological accumulation and absorptive capacity: aggregating Cohen and Levinthal. European Journal Of Development Research, 20(1), 56-73. doi:10.1080/09578810701853181

Da Silva, N., \& Davis, A. R. (2011). Absorptive capacity at the individual level: Linking creativity to innovation in academia. The review of higher education, 34(3), 355-379.

Dewey, J. (1897). My pedagogical creed. School Journal, 54, 77-80. Retrieved from http://dewey.pragmatism.org/creed.htm

Dipboye, R. L. (1982). Self-fulfilling prophecies in the selection-recruitment interview. Academy of Management Review, 7(4), $579-586$. doi:10.5465/AMR.1982.4285247

Ellis, H. C. (1965). The transfer of learning. New York: MacMillan.

Gallagher, K. P., Kaiser, K. M., Simon, J. C., Beath, C. M., \& Goles, T. I. M. (2010). The requisite variety of skills for IT professionals. Communications of the ACM, 53(6), 144-148. doi:10.1145/1743546.1743584

Gutek, G. L. (2000). Historical and philosophical foundations of education: A biographical introduction.

Hawk, S., Kaiser, K. M., Goles, T., Bullen, C. V., Simon, J. C., Beath, C. M., . . Frampton, K. (2012). The information technology workforce: A comparison of critical skills of clients and service providers. Information Systems Management, 29(1), 2-12. doi:10.1080/10580530.2012.634292

Joshi, K. D., Lei, C., Datta, A., \& Shu, H. (2010). Changing the competitive landscape: Continuous innovation through IT-enabled knowledge capabilities. Information Systems Research, 21(3), 472-495. doi:10.1287/isre.1100.0298

Kim, L. (1998). Crisis construction and organizational learning: Capability building in catching-up at hyundai motor. Organization Science, 9(4), 506-521.

Koestler, A. (1964). The act of creation. London: Hutchinson.

Lane, P. J., Koka, B. R., \& Pathak, S. (2006). The reification of absorptive capacity: A critical review and rejuvenation of the construct. Academy of Management Review, 31(4), 833-863. doi:10.5465/AMR.2006.22527456

Lindsay, P., \& Norman, D. (1972). Human information processing. An introduction to psychology: New York: Academic Press.

Minbaeva, D. B., Makela, K., \& Rabbiosi, L. (2007). Absorptive capacity and knowledge transfer: Individual level. Unpublished paper.

Murphy, M. M. (2006). The history and philosophy of education: Voices of educational pioneers: Pearson/Merrill Prentice Hall.

Paulk, M. C., Curtis, B., Chrissis, M. B., \& Weber, C. V. (1993). Capability maturity model, version 1.1. IEEE software, 10(4), $18-27$.

Shawal, M. Pragmatism in education: Study notes. Retrieved from http://www.yourarticlelibrary.com/education/pragmatism-ineducation-study-notes/69152/

Sveiby, K.-E. (2001). A knowledge-based theory of the firm to guide in strategy formulation. Journal of Intellectual Capital, 2(4), 344358.

Taggar, S. (2002). Individual creativity and group ability to utilize individual creative resources: A multilevel model. Academy of Management Journal, 45(2), 315-330. doi:10.2307/3069349

Teece, D. J., Pisano, G., \& Shuen, A. (1997). Dynamic capabilities and strategic management. Strategic Management Journal, 18(7), 509-533.

Wickens, C. D., Gordon, S. E., Liu, Y., \& Lee, J. (1998). An introduction to human factors engineering. New Jersey: Pearson Education.

Zahra, S. A., \& George, G. (2002). Absorptive capacity: A review, reconceptualization, and extension. Academy of Management Review, 27(2), 185-203. 


\section{APPENDIX}

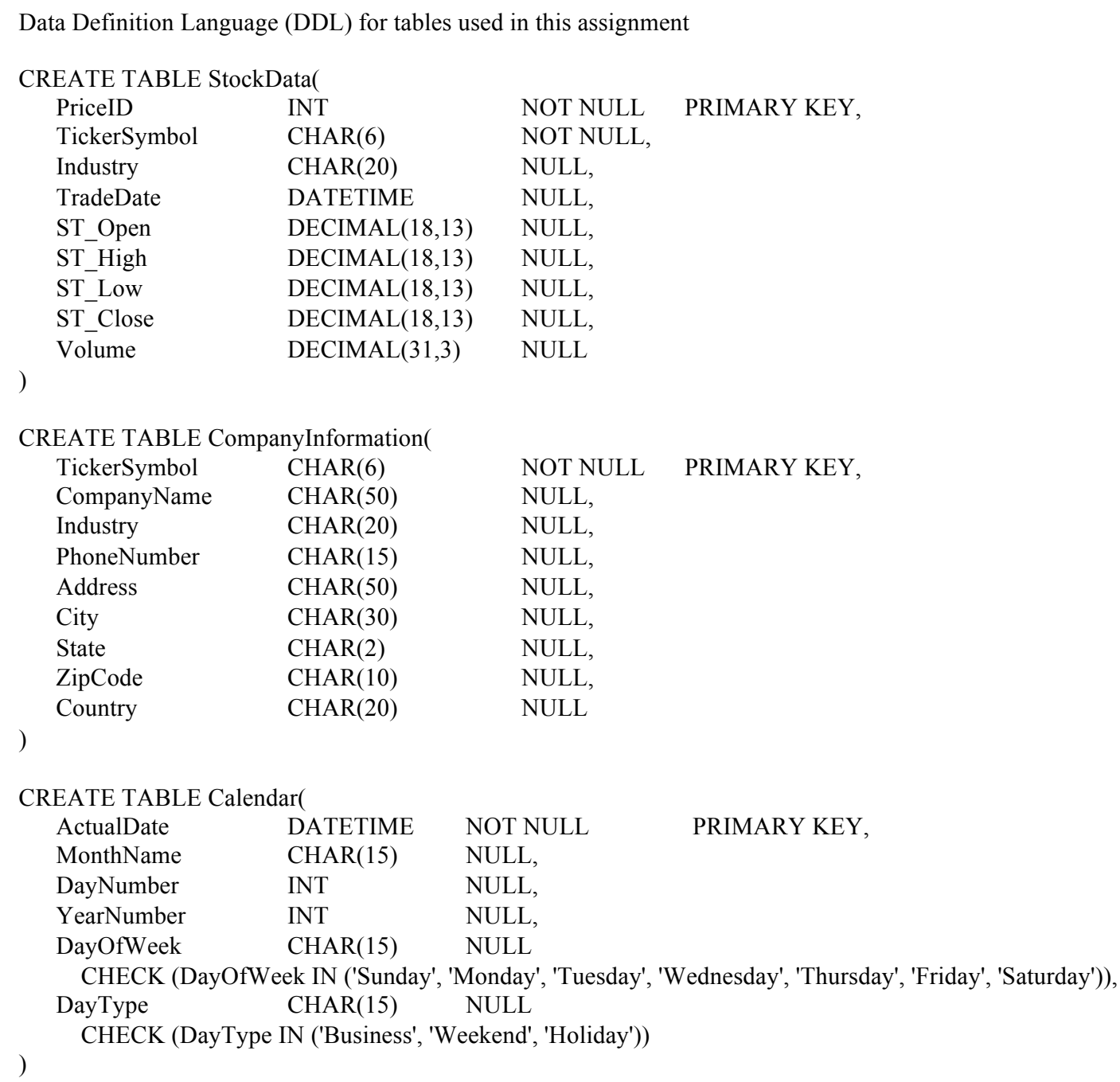

